\title{
The Intermediary Roles of Public Health Nurses (PHNs) in Utilizing Communication Robots (CRs) in Community Health Care Practice
}

\author{
Chihiro Kawai1, Feni Betriana1, Tetsuya Tanioka², Yuko Yasuhara², Hirokazu Ito²,

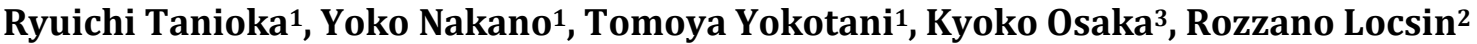 \\ ${ }^{1}$ Graduate School of Health Sciences, Tokushima University, Tokushima, Japan \\ ${ }^{2}$ Department of Nursing, Institute of Biomedical Sciences, Graduate School, Tokushima University, Tokushima, Japan \\ ${ }^{3}$ Department of Psychiatric Nursing, Graduate School of Integrated and Sciences, Kochi University, Kochi, Japan \\ Email: tanioka.tetsuya@tokushima-u.ac.jp
}

How to cite this paper: Kawai, C., Betriana, F., Tanioka, T., Yasuhara, Y., Ito, H., Tanioka, R., Nakano, Y., Yokotani, T., Osaka, K. and Locsin, R. (2019) The Intermediary Roles of Public Health Nurses (PHNs) in Utilizing Communication Robots (CRs) in Community Health Care Practice. Health, 11, 1598-1608. https://doi.org/10.4236/health.2019.1112121

Received: October 21, 2019

Accepted: December 22, 2019

Published: December 25, 2019

Copyright $\odot 2019$ by author(s) and Scientific Research Publishing Inc. This work is licensed under the Creative Commons Attribution International License (CC BY 4.0).

http://creativecommons.org/licenses/by/4.0/

\section{(c) (i) Open Access}

\begin{abstract}
Robot technology is expected to reduce the burden of medical professionals, a concern in the super-aged society. The aim of this article is to determine the intermediary roles of Public Health Nurses (PHNs) in using Communication Robots (CRs) in Community Health care. It is necessary to consider who will manage, and how to draw lines of responsibility when a problem occurs when using robots in the future. Regarding the mediator or intermediary role of PHNs in the use of CRs, PHNs are expected to be cognizant of varieties of robots for use with persons of diverse ages and health levels, as well as of robot performances. As one of the community healthcare workers who service the elderly living in the community, the role of PHNs as mediators or intermediaries is to pay attention to ethical and moral issues while working with CRs to manage the health of the community. Lack of understanding of the intermediary role might create possible ethico-moral issues in the future. Therefore, it is critical for PHNs to understand their role as intermediaries. In doing so, it is expected that older people at home will be able to live peaceful lives, as well as be physically and mentally healthy.
\end{abstract}

\section{Keywords}

Intermediary Roles, Public Health Nurses, Communication Robots, Community Health Care Practice

\section{Introduction}

The aging rate in Japan is reported to reach $26 \%$, becoming the highest aging 
rate in the world [1]. While ASEAN countries usually define "older people" as those aging 60 years and older, the "older people" in Japan are commonly defined as those persons aging 65 years and older [2]. Even though Japan's total population is predicted to decline in the future, the aging rate continues to increase because of the number of older adults [3]. Also, due to the declining birthrate and increasing aging population, it is estimated that a shortage of care workers supporting older adult care will be evident soon [4]. For these reasons, the promotion of independent home life for older adults, the reduction of care burden, and the shortage of health care workers in hospitals and facilities are becoming critical issues in health care.

Robot technology is expected to reduce the health care burden on medical professionals, a concern in the super-aged society. Recently, humanoid robots are being introduced to medical and nursing care environments that are imbued with medical and nursing care functions [3].

According to the Headquarters for Japan's Economic Revitalization, the basic policy is to help people to continue their lives when they reach the age at which they require nursing and medical care [5]. In nursing settings, the robotic nursing equipment can be used to enhance the work efficacy and to reduce the number of workers [5]. Also, through the communication with older people, robots can be used to prevent them from serious disease such as dementia [5].

From this background, reports [6] [7] [8] exist that evaluated the use of robots in the community. However, the history of research on the actual use of robots in hospitals and communities has been at most minimal, and therefore requires more investigation to establish evidence.

Nevertheless, there are studies on robots used for older adults in the community, such as using Telenoids for communication support for older adults [9]. Older adults with Alzheimer's disease showed positive reaction to the Telenoid [9]. Another study in Taiwan explored 33 healthy, community-dwelling Taiwanese older adults who responded at a higher level of acceptance toward the more service-oriented robot than the more companion-oriented robot considering attitude, perceived adaptiveness, and perceived usefulness [10]. A robot-administered cognitive test might have satisfactory reliability and acceptability to community-dwelling older adults if aspects of the test by the researchers can also be successfully automated [11]. Furthermore, caregivers and persons with mild cognitive impairment had higher perceived usefulness and intention to use SAR (Socially Assistive Robots) at the present time, than healthy older adults, thereby confirming that current needs are strongly related to technology acceptance and should influence SAR design [12]. Despite encountering technological issues, patients were mostly positive and accepting of the robot, acknowledging its benefits as a companion [13].

Another study evaluated the design and use of socially assistive robots (SARs) and sensors as in-home therapeutic support for older adults with depression. Companionship, while a desired capability, emerged as insufficient to engage many older adults in long-term use of SARs in their home [14]. Nevertheless, 
communication robot (CR) intervention is not only for communication purposes but also for the possibility of expanding the range of future use of robots as a means of promoting self-care, improving and activating the independence of exercise and movement [15]. Thus, it suggests CRs can be applied not only to medical and nursing care but also to older adults living in the community.

Despite the supporting evidence from the literature about the utilization of robots, little is known regarding CRs use for older adults who are living in the community. In Japan, there is little experience described in using CRs for community care.

A possible ideal role for this aspect of care is public health nurses ( $P H N s)$. PHNs are involved in a wide range of health care practices throughout the human life span-from infants to the elderly who are living in the community. PHNs have a role in supporting health promotion [16], and improving the quality of life [17] of older persons.

One example of the intermediary situation between a CR and a community-based elderly is the revitalization of older people through communication exchanges with CRs. There are reports [9] [18] that some older people have become more at peace with themselves by conversing with CRs. It is, therefore, critical that in order to prevent signs and symptoms of possible depression such as withdrawal and isolation, and live an independent life, the focus of using CRs may need to be the provision of life support devices for communication with older people living in the local community.

The field of nursing that uses advanced technology in practice has not been well developed and cannot be compared with other fields regarding its impact on the use of artificial intelligence in the commercialized industry [19].

In order to build quality relationships between varieties of robots and medical professionals, it is important to determine support activities for the older adults in the context of relationships among "persons, CRs, and other people" rather than the existing relationship of "person to person only" [20]. This can lead to the development of and advance the progressive use of CRs. This can possibly exist with the critical support of data derived from investigations on the intermediary roles of PHNs when CRs are used for community care.

\section{Aim}

The aim of this article is to advance the use of PHNs as intermediaries for community health care using CRs. It summarizes the progress of robot care in Japan, issues concerning utilize CRs are discussed.

\section{Progress of the Robot Care in Japan}

\subsection{Robot Care Equipment Development for 5-Year Plan by Ministry of Health, Labor and Welfare}

A five-year plan for robotic care equipment development has been formulated by the Japanese Government [5]. From the viewpoint of reducing the burden on 
caregivers, the use of robot technology is strongly expected in nursing care settings [5]. This is due to problems of CR marketability, safety, and practicality. In order to overcome these problems, priority areas were identified with the concept of improving ease of use and reducing costs as determined by the Ministry of Economy, Trade and Industry from 2013 [21], and the Japan Agency for Medical Research and Development in 2015 [22]. As a business focus for Medical Research and Development (AMED), "Robot Care Equipment Development and introduction Promotion Project" is currently being implemented [22].

\subsection{Robot Care Equipment Development and Introduction of Business Promotion}

The development and commercialization of robot care equipment as the "Priority field in nursing use of robot technology" was announced by the Ministry of Economy, Trade and Industry and the Ministry of Health, Labor and Welfare based on the needs of nursing care sites [21]. Development assistance was provided for the purpose of commercialization and support in promoting the development, practical application, and introduction of self-supporting caregivers, and in creating an environment such as the development of standards for the introduction of robot equipment to nursing care sites [22].

\subsection{Robot Care Equipment Development and Standardization Project (Development Support Project)}

This project is a successor to the "Robot Care Equipment Development/Introduction Project" that started in 2018 [21]. This project aims to contribute to the realization of a healthy and long-lived society by contributing to the construction of a new manufacturing industry in Japan [21]. This project consists of three areas: [Aid for development project] supporting robot care equipment development, [Standard development/standardization business] that support assistance, and [Effect measurement/evaluation business] that support effect measurement at nursing care sites.

For the priority areas formulated by the Ministry of Economy, Trade, and Industry and the Ministry of Health, Labor and Welfare, assistance for the development of robotic care equipment is prioritized to improve the quality of care and support for older adults' independence based on their human care needs [22].

\subsection{Promotion of Spreading the Use of Nursing Care Robots by Care Equipment Lending Model Project}

Currently, a PHN uses Pepper (by Soft bank) in the Kimotuki town, Kagoshima Prefecture for promoting communication with older people. In local salons and facilities for the older people, PALRO (Fuji Soft) Co., Ltd. [23] and Nippon Electric Company (NEC) are being rented in the city of Saijo, Ehime Prefecture [24]. In Okayama City, Okayama Prefecture, a "Care Equipment Lending Model Project" is being implemented in which care robots which are not covered by care insurance can be rented. Their self-pay ratio is $10 \%$ to use CRs [25]. In Ja- 
pan, 94\% of prefectures [26] [27] are subsidy support for the introduction of nursing care robots in each prefecture (country $2 / 3$, and subsidy ratio of prefecture 1/3) [28]. These projects were set up with the aim of creating a comfortable working environment, such as reducing the burden of nursing care in order to support the rapidly increasing older human population. As a promotion of spreading the use of nursing care robots which are effective in reducing the physical burden on caregivers and improving the efficiency of work, establishments are identified that can rent out this equipment [27].

\subsection{Kanagawa Prefecture "Sagami Robot Industry Special Zone"}

Sagami Robot Industry Special Zone was formulated for the purpose of realizing local safety and security through the practical application of life support robots [6]. In February 2013, the Japanese government was designated as the regional activation synthesis special ward. The purpose was to "ensure the safety and security of citizens' lives through the practical application of life support robots and revitalize the local economy". The first plan (2013-2017) has been working on promoting robot development and demonstration experiments, enlightening and encouraging the accumulation of related industries [29]. In April 2018, the second phase (2018-2022) was approved by the government. The prefectures aim to realize a "society that coexists with robots" by cooperating with related organization, and to share the "life" of the citizens who have reached the age of $100[29]$.

\section{Discussion}

In recent years, CRs have been introduced in nursing care welfare facilities and hospitals and has been used for exercise guidance, conversation, and recreation such as karaoke for older adults [30]. However, several issues needed to be identified and taken into consideration when introducing CRs [31]. Those issues included the consideration of PHNs and robots, their users, and other health providers, technicians, and issues regarding ethics and safety [32]. In relation to those issues, PHNs need to understand their role as intermediaries.

Intermediary is not a new concept. Intermediaries in the field of health care were often practicing as "jobs within jobs" which means that the intermediary operates within the limited rules or regulations decided by the service providers [33]. Steward et al. identified and mapped some of the typical intermediaries operating between supply and use. It is critical to discuss the roles intermediaries play in shaping the use of new technologies and how they are in turn shaped [34]. The role of healthcare providers as intermediaries in a robot-based health system is still not clear, and therefore it is needed to provide the impetus to clarify the definition and roles of PHNs as intermediaries.

In Japan, as the number of older adults living alone increases, it is critical that CRs are not centered on facilities and close to people's lives. Community health professional as an intermediary who understands the performance, merits, and 
demerits of CRs, needs to be designed, proposed, and created as a robot system can provide appropriate services to support families, and to be useful in daily life.

Furthermore, it is necessary that PHNs who are engaged in preventive activities fully understand the functions of HRs and encourage the provision and utilization of robots that meet the purposeful health needs of older people who are in institutions [35].

In order to introduce robots to local communities, it is necessary to gain an understanding of community residents. Besides that, it is also important that PHNs also feel the necessity to use a robot. In the future, with the aging society, it will be more important to continue monitoring at home and support local activities.

PHNs, as local intermediaries and robot intermediaries should find the optimal use of humans and CRs by finding usage methods that suit CRs for a wide range of age groups such as prevention of nursing care, support for childcare, and education.

According to the International Council of Nurses (ICN), Code of ethics for nurses revised 2012, nurses have four fundamental responsibilities: to promote health, to prevent illness, to restore health and to alleviate suffering [36]. The need for nursing is universal. Inherent in nursing is a respect for human rights, including cultural rights, the right to life and choice, to dignity and to be treated with respect. Nursing care is respectful of and unrestricted by considerations of age, color, creed, culture, disability or illness, gender, sexual orientation, nationality, politics, race or social status. Nurses render health services to the individual, the family and the community and coordinate their services with those of related groups [36].

As an ethic of PHNs activities (Note: in Japan, PHN license is required in addition to nurse license to work as PHN) [37] [38], to support local residents to improve their quality of life while living independently, they must identify local health issues and respond to individual health issues. In addition, PHNs have to create and distribute social resources like CRs fairly. PHNs need to consider CRs as a social resource. It is important for PHN to enter between the community and the robot as an intermediary.

The role of PHNs also includes properly spreading CRs in the community. However, there also may be problems that occur in spreading CRs. Thus, PHNs need to have the creativity and adaptability for advanced technologies.

In addition, there is a moral issue in how far a robot can make human thoughts and judgments in order to build a human-robot relationship when using CRs in a community [39]. This may cause moral problems, such as whether the current situation is prioritized in relation to human emotions and the current situation that robots prioritize in data can be matched or are in line with that [38].

PHNs need to understand the ethical aspects of personal information leakage [32] and robot control function [33] when using CRs. Another problem is that 
the AI function installed in the CR is in the developmental stage, and it is not possible to respond appropriately to the target of older person's conversation.

However, it might be possible to install artificial consciousness to advanced CRs imbued with Super Artificial Intelligence in the future, their ability of those CRs will increase and it might enable them to respond more like human [40], including possible complain when older adults say the same thing over and over. This condition might create upset, disappointment, or other emotional disturbance for older adults. Thus, it needs to be taken into consideration that future CRs should be carefully programmed to assure not only physical but also mental safety for the community residents.

As one of the community healthcare workers who service the older people living in the community, the role of PHNs as mediators or intermediaries are to pay attention to ethical and moral issues while working with CRs to manage the health of the community. The overall intermediary roles are shown in Table 1.

Due to various types of CRs, it is important to continue the examination and discuss other health care robots for future research. PHNs need to consider two perspectives by using CRs. First, it is important to understand the characteristics by actually utilize CRs. In doing so, PHNs can provide adequate CRs to meet various kinds of support and assistance for people in the community. Second, it is critical that PHNs train themselves as intermediaries to utilize CRs and should develop a method for efficiently use CRs.

Table 1. Expected intermediary roles to PHNs using CRs in the community.

1) Understanding the performance, merit and demerits of CRs.

2) Engaging in preventive activities involving CRs [35].

3) Understanding the functions of CRs and encouraging the provision and utilization of CRs.

4) Meet the needs of community residents by use CRs [35].

5) Finding the methods that are suitable for using CRs for the community residents' health condition.

6) Identifying local health issues and responding to individual health issues.

7) Properly spreading CRs in the community.

8) Identifying issues and concerns of ethics, moral, security and safety [32].

9) Being in line with possible resources for ethical activity.

10) Assuring physical and mental safety of the community residents during the interaction with CRs.

\section{Conclusions}

It is necessary to consider who will manage and draw the lines of responsibility when a problem occurs in using robots in the future. These ethical concerns can be addressed as PHNs activities. Regarding the mediator or intermediary role of PHNs, they are expected to be cognizant of varieties of robots for use with persons of diverse ages and health levels, as well as robot performances. After considering the advantages and disadvantages of using robots, it is necessary to provide older adults at their homes with CRs according to their situation of health care need. Also, when using these robots, PHNs, or the group leader should have a license on how to operate the CRs.

During the program, the PHNs are on the side of the user to ensure the quality of service so that the CRs can be operated smoothly. PHNs are required to 
play a role as an intermediary who supports the effective use of CRs. This is due to the decreased population in communities due to the nuclear family, which is currently considered a problem in Japan. With CRs, these will enable all people, including older people who are living alone to be able to have independent lives. PHNs need to play an intermediary role in the use of CRs in the community. They are envisioned to fill the gap between the shortage of health care workers, and the health care needs of people in the community.

As one of the community healthcare workers who service the older people living in the community, the role of PHNs as mediators or intermediaries is to pay attention to ethical and moral issues while working with CRs to manage the health of the community. Lack of understanding of the intermediary role when using CRs might create possible ethico-moral issues in the future. Therefore, it is critical for PHNs to understand their role as intermediaries. In doing so, it is expected that older people at home to live a peaceful life both physically and mentally healthy.

\section{Acknowledgements}

This study was supported by Pfizer Health Research Foundation.

\section{Conflicts of Interest}

The authors declare no conflicts of interest regarding the publication of this paper.

\section{References}

[1] Permanent Mission of Japan to the United Nations (2016) Mainstreaming Gender and Aging in the SDGs, Presentation by Okamura Y. http://www.un.emb-japan.go.jp/jp/statements/okamura071316.html

[2] Ministry of Health, Labor, and Welfare of Japan (2014) Report of the Study Group for Japan's International Contribution to "Active Aging”.

https://www.mhlw.go.jp/file/05-Shingikai-10501000-Daijinkanboukokusaika-Kokus aika/0000044929.pdf

[3] Tanioka, R., Sugimoto, H., Yasuhara, Y., Ito, H., Osaka, K., Zhao, Y., Kai, Y., Locsin, R. and Tanioka, T. (2019) Characteristics of Transactive Relationship Phenomena among Older Adults, Care Workers as Intermediaries, and the Pepper Robot with Care Prevention Gymnastics Exercise. The Journal of Medical Investigation, 66, 46-49. https://www.jstage.jst.go.jp/article/jmi/66/1.2/66_46/_pdf

[4] Lopez, M. (2012) Reconstituting the Affective Labor of Filipinos as Care Workers in Japan. Global Networks, 12, 252-268. https://doi.org/10.1111/j.1471-0374.2012.00350.x

[5] The Headquarters for Japan's Economic Revitalization (2015) New Robot Strategy (Japan's Robot Strategy: Vision, Strategy, Action Plan). https://www.meti.go.jp/english/press/2015/pdf/0123_01b.pdf

[6] Tokyo Health and Welfare Bureau, Aged Society Countermeasure Department (2018) Report on Robot Care/Welfare Equipment Utilization Support Model Project. (In Japanese)

http://www.fukushihoken.metro.tokyo.jp/kourei/shisaku/jisedaikaigo/robotmodel.fi 
les/moderu-houkokusyo.pdf

[7] Ministry of Health, Labor, and Welfare of Japan. (2018) Report on Welfare Equipment/ Care Robot Practical Application Support Project (In Japanese)

http://www.techno-aids.or.jp/robot/file29/02jigyo.pdf

[8] Welfare Information for Citizens Office Hascup (2018) Mail Mini Comi "Welfare Information for Citizens". (In Japanese)

https://www.mhlw.go.jp/file/04-Houdouhappyou-12304250-Roukenkyoku-Koureis hashienka/0000201027.pdf

[9] Kuwamura, K., Nishio, S. and Sato, S. (2016) Can We Talk through a Robot as If Face-to-Face? Long-Term Fieldwork Using Teleoperated Robot for Seniors with Alzheimer's Disease. Frontier in Psychology, 7, 1066.

https://doi.org/10.3389/fpsyg.2016.01066

[10] Chu, L., Chen, H., et al. (2019) Identifying Features that Enhance Older Adults' Acceptance of Robots: A Mixed Methods Study. Gerontology, 65, 441-450. https://doi.org/10.1159/000494881

[11] Takaeda, K., Kamimura, T.E., Inoue, T. and Nishiura, Y. (2019) Reliability and Acceptability of Using a Social Robot to Carry out Cognitive Test for Community-Dwelling Older Adults. Geriatrics and Gerontology International, 19, 552-556. https://doi.org/10.1111/ggi.13655

[12] Pino, M., Boulay, M., Jouen, F. and Rigaud, A.S. (2015) “Are We Ready for Robots that Care for Us?” Attitude and Opinions of Older Adults towards Socially Assistive Robots. Frontiers in Aging Neuroscience, 7, 141. https://doi.org/10.3389/fnagi.2015.00141

[13] Orejana, J.R., Macdonald, B.A., Ahn, H.S., Peri, K. and Broadbent, E. (2015) Healthcare Robots in Homes of Rural Older Adults. Proceedings of the 7 th International Conference on Social Robotics, ICSR 2015, France, 26-30 October 2015, 512-521. https://doi.org/10.1007/978-3-319-25554-5_51

[14] Randall, N., Bennet, C.C., et al. (2019) More Than Just Friends: In-Home Use and Design Recommendations for Sensing Socially Assistive Robots (SARs) by Older Adults with Depression. Paladyn, Journal of Behavioral Robotics, 10, 237-255. https://doi.org/10.1515/pjbr-2019-0020

[15] Dahl, T.S. and Boulos, M.N.K. (2014) Robots in Health and Social Care: A Complementary Technology to Home Care and Telehealthcare? Robotics, 3, 1-21. https://doi.org/10.3390/robotics3010001

[16] Serradilha, A.F.Z., Duarte, M.T.C. and Tonete, V.L.P. (2018) Health Promotion by Nursing Technicians from the Nurses' Perspective. Revista Brasileira de Enfermagem, 72, 979-987. https://doi.org/10.1590/0034-7167-2018-0552

[17] Schaffer, M.A., Kalfoss, M. and Glavin, K. (2017) Public Health Nursing Interventions to Promote Quality of Life in Older Adult Populations: A Systematic Review. Journal of Nursing Education and Practice, 7, 92-106. https://doi.org/10.5430/jnep.v7n11p92

[18] Sabelli, A.M., Kanda, T. and Hagita, N. (2011) A Conversational Robot in An Elderly Care Center: An Ethnography Study. Proceedings of the 6th ACM/IEEE International Conference on Human-Robot Interaction, Lausanne, 6-9 March 2011, 37-44. https://doi.org/10.1145/1957656.1957669

[19] Pepito, J.A. and Locsin, R. (2019) Can Nurses Remain Relevant in A Technologically Advanced Future? International Journal of Nursing Sciences, 6, 106-110. https://doi.org/10.1016/j.ijnss.2018.09.013

[20] Tanioka, T. (2017) The Development of the Transactive Relationship Theory of 
Nursing (TRETON): A Nursing Engagement Model for Persons and Humanoid Nursing Robots. International Journal of Nursing \& Clinical Practices, 4, 8. https://doi.org/10.15344/2394-4978/2017/223

[21] Ministry of Economy, Trade, and Industry (2014) Revision of the Four Areas to Which Robot Technology Is to Be Introduced in Nursing Care of the Elderly. https://www.meti.go.jp/english/press/2014/0203_02.html

[22] Japan Agency for Medical Research and Development (2019) Project to Promote the Development and Standardization of Robotic Devices for Nursing Care. https://www.amed.go.jp/en/program/list/02/01/009.html

[23] The Association for Technical Aids (ATA) (2000) Technical Aids Information System (TAIS). (In Japanese)

http://www.techno-aids.or.jp/WelfareItemDetail.php?RowNo=1\&YouguCode $1=017$ 60\&YouguCode $2=000001$

[24] Saijo City Official Website (2015) Why Do Not You Take Advantage of the AI Robot to Watch the Elderly. (In Japanese)

https://www.city.saijo.ehime.jp/soshiki/hokatsushien/h30komyuroboriyousyabosyu u.html

[25] Nursing Robot Online (2019) Nursing Robot Online, A Care Robot Can Be Rented at $10 \%$ Burden! Okayama City's "Care Equipment Lending Model Project". (In Japanese) https://kaigorobot-online.com/news/120

[26] Nursing Robot Online (2019) By Municipality! List of Subsidies for Nursing Care Robots. (In Japanese) https://kaigorobot-online.com/subsidy

[27] Hokkaido (2019) Subsidy for Nursing Robot Introduction Support Project Cost. (In Japanese) http://www.pref.hokkaido.lg.jp/hf/khf/informathion-robot-.htm

[28] Ministry of Health, Labor and Welfare (2018) Support for the Introduction of Nursing Care Robots Utilizing the Regional Medical Care Comprehensive Securing Fund. (In Japanese) https://www.mhlw.go.jp/content/12300000/000529832.pdf

[29] Kanagawa Prefecture (2019) Sagami Robot Industry Special Zone. (In Japanese) http://www.pref.kanagawa.jp/docs/sr4/cnt/f430080/index.html

[30] Tanioka, T., Yasuhara, Y., Dino, M.J.S., Kai, Y., Locsin, R.C. and Schoenhofer, S.O. (2019) Disruptive Engagements with Technologies, Robotics, and Caring: Advancing the Transactive Relationship Theory of Nursing. Nursing Administration Quarterly, 43, 313-321. https://doi.org/10.1097/NAQ.0000000000000365

[31] Tanioka, R., Locsin, R., Yasuhara, Y. and Tanioka, T. (2018) Potential Legal Issues and Care Implications during Care-Prevention Gymnastic Exercises for the Elderly Using Pepper in Long Term Health Care Facilities. Intelligent Control and Automation, 9, 85-93. https://doi.org/10.4236/ica.2018.93007

[32] Yasuhara, Y., Tanioka, R., Tanioka, T., Ito, H. and Tsujigami, Y. (2019) Ethico-Legal Issues with Humanoid Caring Robots and Older Adults in Japan. International Journal for Human Caring, 23, 141-148. https://doi.org/10.20467/1091-5710.23.2.141

[33] Lahtiranta, J. (2017) Mediator-Enable for Successful Digital Health Care. Finnish Journal of eHealth and eWelfare, 9, 284-298.

[34] Steward, J. and Hyysalo, S. (2008) Intermediaries, Users, and Social Learning in Technological Innovation. International Journal of Innovation Management, 12, 295-325. https://doi.org/10.1142/S1363919608002035

[35] Mccue, T.J. (2017) Redshift by Autodesk, Helpers, Conversation Partners, Mediators-Healthcare Robots Change the World of Care. (In Japanese) 
https://www.autodesk.co.jp/redshift/health-care-robots/

[36] International Council of Nurses (2012) The ICN Code of Ethics for Nurses. https://www.icn.ch/sites/default/files/inline-files/2012_ICN_Codeofethicsfornurses \%20eng.pdf

[37] Association of Public Health Nurses (2019) What Is a PHN? http://www.phnurse.org/What-is-Public-Health

[38] Japanese Nursing Association (2019) Japanese Nursing Association. Overview of Japanese Nursing System. https://www.nurse.or.jp/jna/english/nursing/system.html

[39] Stahl, B.C. and Coeckelbergh, M. (2016) Ethics of Healthcare Robotics: Towards Responsible Research and Innovation. Robotics and Autonomous Systems, 86, 152-161. https://doi.org/10.1016/j.robot.2016.08.018

[40] Zhao, Y., Kai, Y. and Tanioka, T. (2019) Discovering Humanoid Robot Consciousness Within Caring Science. International Journal of Human Caring, 23, 121-131. https://doi.org/10.20467/1091-5710.23.2.121

\section{Abbreviation List}

PHNs, Public Health Nurses; CRs, Communication Robots; SAR, Socially Assistive Robots; AMED, Agency for Medical Research and Development; NEC, Nippon Electric Company; ICN, International Council of Nurses. 